\title{
The Global Price of Oil, QE and the US High Yield Rate
}

\author{
A. (Tassos) G. Malliaris \\ Loyola University Chicago, tmallia@luc.edu \\ Mary E. Malliaris \\ Loyola University Chicago, mmallia@luc.edu
}

Follow this and additional works at: https://ecommons.luc.edu/business_facpubs

Part of the Business Commons

\section{Author Manuscript}

This is a pre-publication author manuscript of the final, published article.

\section{Recommended Citation}

Malliaris, A. (Tassos) G. and Malliaris, Mary E.. The Global Price of Oil, QE and the US High Yield Rate. Journal of Economic Studies, 47, 7: 1849-1860, 2020. Retrieved from Loyola eCommons, School of Business: Faculty Publications and Other Works, http://dx.doi.org/10.1108/JES-01-2020-0025

This Article is brought to you for free and open access by the Faculty Publications and Other Works by Department at Loyola eCommons. It has been accepted for inclusion in School of Business: Faculty Publications and Other Works by an authorized administrator of Loyola eCommons. For more information, please contact ecommons@luc.edu.

\section{(c) (i)}

This work is licensed under a Creative Commons Attribution 4.0 International License.

(c) Emerald Publishing Limited, 2020. 


\title{
The Global Price of Oil, QE and the U.S. High Yield Rate
}

\author{
A.G. MALLIARIS, Walter F. Mullady, Sr. Professor of Economics \\ Quinlan School of Business, Loyola University Chicago \\ 16 East Pearson Street, Chicago, Illinois 60611 \\ tmallia@luc.edu \\ MARY MALLIARIS, Professor of Information Systems \\ Quinlan School of Business, Loyola University Chicago \\ 16 East Pearson Street, Chicago, Illinois 60611 \\ mmallia@luc.edu
}

\begin{abstract}
During the Global Financial Crisis of 2007-2009, the price of crude oil dropped markedly from $\$ 140$ per barrel in June 2008 to $\$ 40$ in early 2009. As Quantitative Easing allowed the U.S. economy to stabilize and return to slow growth, oil prices increased and averaged $\$ 100$ during 2010-13. Then in June 2014, they plunged again dramatically to $\$ 40$. This paper proposes a model that describes the price of oil as depending on six inputs: Federal Assets accumulated by the Fed during the period of Quantitative Easing, the 10-Year Treasury Note rate, the price of copper, the Trade Weighted dollar, the S\&P 500 Index and the U.S. High Yield Rate for Bonds rated CCC or below. Making use of 771 overlapping 52-week regressions to capture short run dynamics we find that Quantitative Easing was statistically significant only during 2009-10, while the U.S. High Yield Rate played a more significant role, both during and after the crisis.
\end{abstract}

Keywords: Quantitative Easing, Price of Oil, High Yield Bond rate, 10-Year Treasury Note rate, Fracking Technology.

JEL Classification: C10; C45; C58; E52; E58.

Date of this draft: February 1, 2020. Accepted for publication in the Journal of Economic Studies. 


\section{The Global Price of Oil, QE and the U.S. High Yield Rate ${ }^{1}$}

\section{INTRODUCTION}

Global oil prices were stable from 1986 to 2002, fluctuating around \$20. However, the price of oil from 2003 to 2018 varied enormously. From a low oil price of $\$ 20$ in early 2002, prices moved erratically to a high price of $\$ 133$ in July 2008, prior to the Global Financial Crisis of 2007-09, then collapsed to under $\$ 40$ in February 2009. Oil prices slowly recovered to $\$ 110$ in April 2011. After a few years of reduced volatility, the price of oil crashed again back to $\$ 30$ in February 2016. By the end of December 2018, the price was back to $\$ 45$.

In this paper we focus on weekly crude oil spot prices during this volatile period from 2003 to 2018 and propose a financial model to explore these swings. The period we consider begins in January 2003 and concludes at the end of 2018. We ask, which of our financial variables can explain the behavior of oil prices during this period of high volatility. Can an economic hypothesis be proposed to explain such notable price changes? Since this period includes the Global Financial Crisis of 2007-09 and the dramatic response of the Federal Reserve with its unconventional monetary policy, these monetary policies are pivotal in the formulation of our financial model.

To offer an explanation for these dramatic price changes in oil during the last 18 years, we motivate the discussion of our financial model with a brief literature review in the next section. Then in Section 3, we explain the central idea that constitutes the original contribution of this work and emphasizes its significance. We proceed to formulate our hypothesis in section 4 . Section 5 describes our econometric methodology and also contains an analysis of the results. A summary of our findings is given in the last section. 


\section{LITERATURE REVIEW}

The seminal paper that analyzes the role of oil in the U.S. economy is Hamilton (1983). This paper carefully examines the influence of crude oil price shocks on the macroeconomy with a focus on U.S. recessions. Hamilton (1983) documents that 7 out of 8 U.S. recessions since World War II to the time of his writing were preceded, with a lag of about 3 quarters of a year, by a dramatic increase in crude oil prices. The author is careful to emphasize that his work does not prove that oil price shocks caused these recessions; however, there is econometric evidence to claim that these oil price shocks were an important contributing factor. In a companion paper, Hamilton (1985) extends his econometric work with a detailed narrative to argue that oil price increases represent systematic, endogenous outcomes associated with U.S. business cycle peaks. Bernanke, Gertler, and Watson (1997) expand the Hamilton $(1983,1985)$ analysis and introduce the role of monetary policy, in addition to the price of oil, as determinants of macroeconomic fluctuations. These authors demonstrate empirically that essentially all postwar U.S. recessions were preceded by both oil price increases and also by a tightening of monetary policy.

Barsky and Kilian (2001) and Kilian (2008) go further than Bernanke, Gertler and Watson (1997) to argue that macroeconomic fundamentals of oil supply and demand, although very important, cannot alone explain the major oil price increases in the 1970s. Monetary factors also need to be considered.

The theme of the interplay between oil prices, business cycles and U.S. monetary policy was broadened after the financial crisis to include global economic factors with particular emphasis on the rapid economic growth of China during the past 25 years. A sample of such developments is presented in Cashin, Mohaddes, Raissi and Raissi (2014) who examine the macroeconomic effects of oil price shocks for a large sample of countries; also Narayan, Sharma, 
Poon and Westerlund (2014) test whether oil prices influence economic growth for a sample of 28 developed and 17 developing countries and find some evidence for out-of-sample predictability with nominal rather than real oil prices.

Hamilton (2009) reviews several theories that may help explain oil price increases prior to and at the beginning of the Global Financial Crisis. He surveys supply and demand fundamentals for oil, examines the factors that drive crude oil price changes, and discusses the statistical behavior of such prices with an emphasis on statistical predictability. In his paper, Hamilton succeeds in expressing the complexity of the global oil market that is produced by many factors: the global fundamentals of supply and demand, the oligopolistic market structure with the presence of OPEC, arbitrage between spot and futures markets, storage, cost of carry, oil as an exhaustible resource, speculation, the global business and financial cycles, monetary policy, geopolitical risks, and expectations of business, consumers and governments about future prices.

Smith (2009) also addresses the turbulent price dynamics of the global oil market, thus complementing Hamilton (2009). Smith employs meticulous logic to describe the factors that contribute to oil volatility instead of focusing on econometric modeling that is the methodological approach of Hamilton (2009). Pinno and Serletis (2013) focus on oil price uncertainty and industrial production, while Kilian $(2008,2009)$ investigates the effects of volatile oil prices on U.S. macroeconomic aggregates. Kilian emphasizes that researchers, in estimating the impact of oil markets to the rest of the economy, implicitly consider causation from oil to the macroeconomy but ignore the reverse causality that is also present.

Bhar and Malliaris $(2011,2015)$ and Tsai $(2015)$ describe the behavior of oil prices during the crisis. Salvatore (2010), Bernanke (2012) and Kuttner (2018) give detailed accounts 
of the Global Financial Crisis. A major shock, such as the 2007-09 Crisis, also produced a significant upsurge in the volatility of oil prices. Often, such volatility persists as hedging and speculation activities persevere. Yin and Zhou (2016) develop this theme of oil speculation and Morana (2013) also investigates oil speculation, preferences and volatility shocks using a macrofinancial-econometric model with fiscal and monetary responses. Oil speculation during periods of major uncertainty influences the global price of oil, but in the longer-run its impact disappears.

Lastly, Baumeister and Kilian (2016a) review the causes of the major oil price shocks since the early 1970s, episode by episode and succeed with their definitive and insightful chronicle to explain why oil prices keep surprising financial markets, policy makers and researchers. The authors list many causes of past major oil price fluctuations in their chronological exposition, but as the number increases, predicting the future trigger of the next oil price shock becomes very challenging.

\section{ORIGINALITY, CONTRIBUTION AND ECONOMIC INTUITION}

These representative studies examined in the literature review develop theoretical models, apply rigorous econometric techniques and establish empirical connections between the price of oil and several influences that drive price changes. Fundamentals of supply and demand for oil, macroeconomic variables, monetary variables, trading and speculation, and global financial influences are among the main factors considered. In the formulation of our model regarding the behavior of oil prices during the 2003-2018 period, we employ some of these factors and supplement our analysis with other variables that play an important role during this period.

In this contribution, we introduce the hypothesis that unconventional monetary policy has impacted the price of oil both directly and indirectly. The direct influence of unconventional 
monetary policy is discussed in detail in Bernanke (2010, 2014, 2020), who articulates the portfolio-balance channel of Quantitative Easing (QE). This channel of QE works by increasing the demand for government bonds and mortgage backed securities that usually increases their prices and lowers their yields. Portfolio rebalancing in turn decreases longer-term yields of corporate bonds. The first round of QE occurred when financial markets stabilized early in 2009 and unemployment steadied around 10\%. The end of the Great Recession in June 2009, and the weak economic recovery that followed, necessitated the continuation of QE to target the reduction of unemployment. Reduction in unemployment meant increases in national income and in turn increases in the demand for oil. When the first QE was followed by a second QE and then a third one, the direct effect was the recovery of oil prices because of the strengthening of oil demand. Fiscal and monetary policies in other countries and, in particular, in China during this period from 2009 to 2014 also stimulated the global demand for oil that lifted the price to $\$ 100$ in 2012.

The originality of our contribution lies in the indirect or unintended influence of this unconventional monetary policy on the supply of U.S. oil and the reduction of global oil prices in mid-2014. This happened because the dramatic expansion of the balance sheet of the Federal Reserve Bank with QE1, QE2 and QE3 during the 2009-2014 period also slowly reduced the High Yield Bond rates. This in turn financed investments in the fracking technology that led to increased U.S. production of oil, thus contributing to oil price declines during 2014-15

The U.S. Energy Information Administration (EIA) reports that in 2008 the U.S. produced 5 million barrels of oil per day while in 2018 this amount more than doubled to 11 million barrels per day. During 2018, about 6.5 million barrels per day of crude oil, i.e. 59\%, were produced directly from tight oil resources. Tight oil is oil embedded in low-permeable 
shale, sandstone, and carbonate rock formations. Technological advances in horizontal drilling and hydraulic fracturing enabled the extraction of oil from these underground shale formations. These technologies were known for some time but judged uneconomical at low oil prices near \$30. Increased oil prices after the Global Financial Crisis, combined with very low High Yield rates, financed these very risky fracking investments and contributed to the dramatic increase of U.S. oil production. However, this indirect impact of QE via decreasing the High Yield rate works well as long as global oil prices remain reasonably high. This is because High Yield loans are collateralized on the expected value of future oil output that decreases with oil price drops.

So the indirect impact is driven both by borrowing costs to finance exploration and production of oil that decline as High Yield rates decline but also by future expected earnings that are determined by expected future oil prices.

\section{MODEL, HYPOTHESIS FORMULATION, AND DATA}

We formulate the hypothesis that the price of oil during the period from January 1, 2003, to December 31, 2018, can be explained by a simple financial model that relates changes in the price of oil to changes in a few key independent variables though the relative importance of the variables will change over time. The selection of independent variables is guided by the bibliographical review and also variables that became important during the Global Financial Crisis of 2007-09. The model proposed is as follows:

$D(\log P$ of Oil at $t)=c 0+c 1 * D(\log$ Fed Assets at $t)+c 2 * D($ Ten Year Note at $t)$

$+c 3 * D(\log$ Price of Copper at $t)+c 4 * D(\log$ Price of Trade-Weighted Dollar at $t)$

$+c 5 * D(\log S \& P 500$ at $t)+c 6 * D($ US High Yield CCC Rate at $t)$ 
During the period under investigation, the dominant economic event was the Global Financial Crisis and the bold responses to this crisis by central banks under the leadership of the Federal Reserve. Therefore, we propose a financial model motivated by the eminence of financial conditions during this period driving the real macroeconomy, including oil. The independent variables we plan to use in equation (1) are: Fed Assets accumulated by the 3 rounds of QE by the Fed, the 10-Year Treasury Note rate, the Price of Copper, the Trade Weighted Dollar Index, the S\&P 500 Index and the U.S. High Yield Rate. This last one is a risk measure for junk bonds, obtained from ICE Benchmark Administration Limited (IBA), retrieved from FRED, Federal Reserve Bank of St. Louis. (The symbol for this rate is BAMLH0A3HYC and is reported as a spread from a corresponding Treasury yield curve). Its inclusion in our financial model is novel since it has not received much attention in the oil literature. These six independent variables we consider important to explain the behavior of oil prices during our sample period ${ }^{2}$.

The data used are publically available data at FRED, Yahoo, and macrotrends.net. We used a weekly frequency starting on January 1, 2003, and ending on December 31, 2018, for 823 observations for each variable.

\section{METHODOLOGY AND RESULTS}

The literature review of section 2, particularly the insightful surveys of Hamilton (2009), Smith (2009) and Baumeister and Kilian (2016a), vividly demonstrates the multiple approaches employed by researchers to obtain a proper understanding of the oil market. We do not claim causality nor do we have an explicit multi-equation macroeconomic model that describes the channels these independent variables go through to influence the price of oil. Instead, we 
hypothesize that the complex behavior of oil prices could be understood as being statistically determined by these six economic variables that influence the price of oil described in (1) on the basis of reasonable economic relationships that dominated during the period under investigation.

Our interest and contribution is in capturing the statistical significance of these six inputs in the short-run price dynamics of oil. We recognize that fitting such a model for the entire period of 15 years may not perform satisfactorily, but more importantly, may fail to reveal the changing patterns of this relationship. The methodology we choose to employ is rolling 52-week regressions to help us capture the short-run dynamics of the oil-price-financial-variables sector of the economy. Rolling regressions are appropriate as a statistical tool when estimates of the coefficients are expected to vary. This is consistent with our model that includes three different periods; one before the crisis when there was no QE; the next is during the crisis with $\mathrm{QE}$ and finally after QE ended. There are no theoretical grounds to search for cointegrating relationships because we are not investigating a single long-run relationship among the variables.

We estimate the regression model of (1) with a sample size of 52 weeks beginning with the January 8, 2003 date. We then drop the first set of observed values and add the $53^{\text {rd }}$ row of data and continue in this fashion to 2018. We use 52 weeks in our sample to track developments over one year. Also, QE evolved in windows of approximately one to two years. Such rolling regressions produce values for the six coefficients that change in view of the overlapping 51 observations. Our statistical output consists of 771 regressions with their corresponding statistics. These changes capture the emergence and decay of significance among the independent variables and demonstrate the short-lived versus the more enduring importance among these inputs. 
Taking natural logarithms when appropriate (for all variables except for the 10-Year Treasury Note rate and the High Yield rate) reduces scaling issues so the price differences of oil are not regressed on differences in Fed Assets measured in billions of dollars. Logarithms also allow for possible nonlinearities. Finally, considering one period differences in logs as in (1) ensures stationarity ${ }^{3}$.

By running 52-week rolling regressions of our model described in equation (1), we estimate six coefficients, an R-squared value, and statistics to determine their significance. The coefficients estimated and their corresponding statistics are dated at the last date in the sample used for calculations. For example, the very first value is the result computed using the very first sample of 52 weeks in 2003 and dated 12/31/2003.

We begin our analysis with an overview of the results. Graph 1 illustrates the R-square values for each one of the 771 rolling regressions.

\section{Graph 1. R-squared}

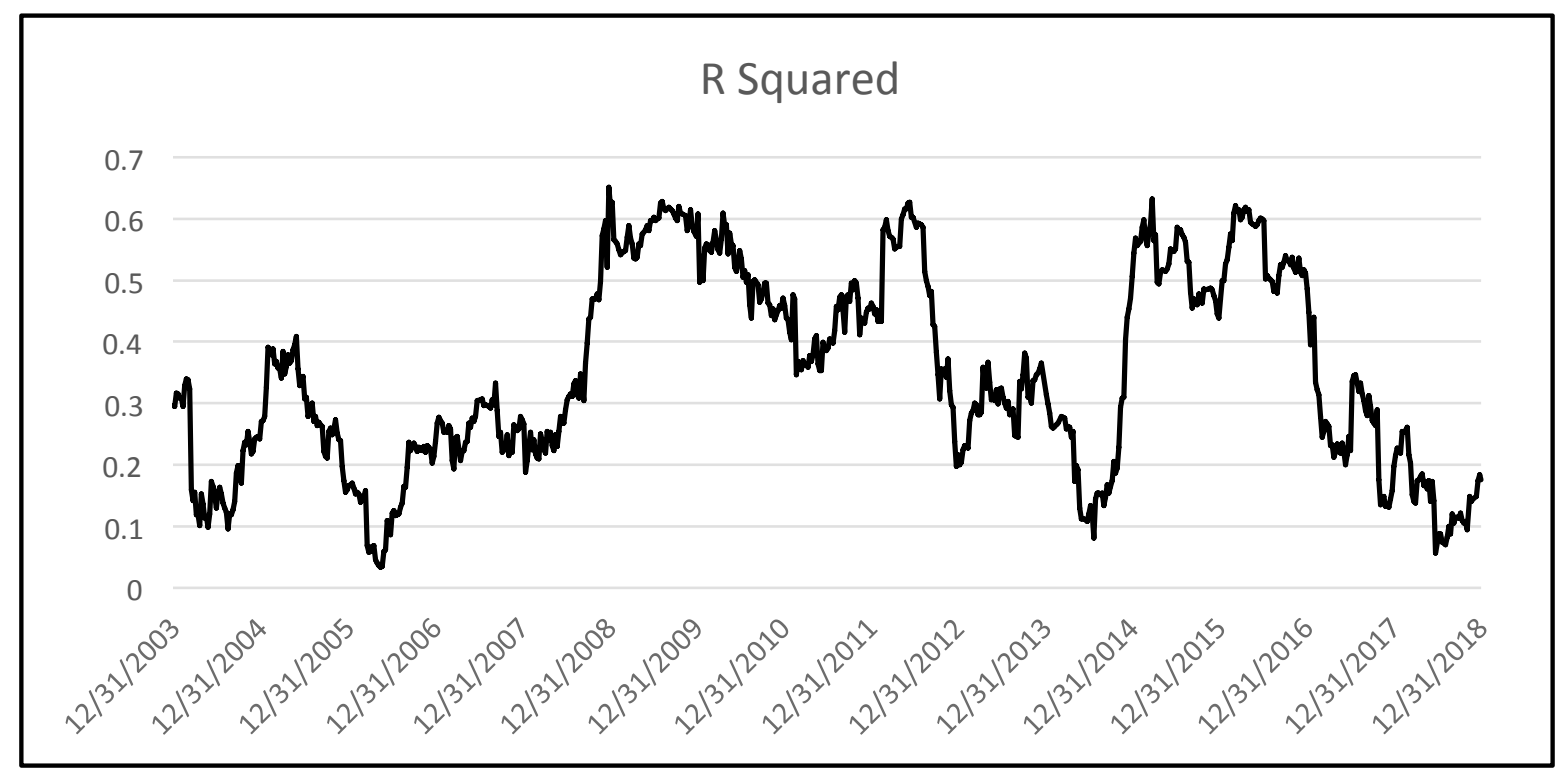


The values range between .03 and .62 . We find that 552 out of 771 regressions had variable coefficients significantly different from 0 . That is, for $72 \%$ of our rolling regressions we cannot reject the null hypothesis that all six coefficients in equation (1) are equal to zero. We conclude that there is statistical support for the proposed financial model in equation (1).

Examining Graph 1, we observe that the model performs well in specific periods. One period includes the Global Financial Crisis of 2007-09 and the other contains the termination of QE from late 2014 to 2017. During these periods the financial model explains approximately $40 \%$ to $65 \%$ of the variability in oil prices. In view of the excessive volatilities of most financial variables during these periods, the satisfactory performance of the model is noteworthy.

Next, we focus on each of the six coefficients in model (1) estimated by the 771 rolling regressions. This rich output of results could not be obtained by estimating only one regression with all 823 weekly observations. We proceed by exhibiting and discussing the value of each coefficient along with its $95 \%$ level confidence band. To facilitate the evaluation of each coefficient's significance, Table 1 summarizes the number of times each coefficient was significantly different from 0 and helps us conclude that QE and 10-Year Treasury Note rates only had a limited direct impact on oil markets. Actually QE significantly impacts oil prices in our model the least number of times. The value of the dollar and the U.S. equity markets affected the oil market but to a lesser degree than the best three explanatory variables: copper, High Yield rate and Trade Weighted dollar index.

Table 1. Number of times the Null Hypothesis that a coefficient $=0$ is rejected

\begin{tabular}{|l|c|}
\hline & P-value $<=.05$ \\
\hline C1, DLnFedAst & 9 \\
\hline C2, DTrRate & 23 \\
\hline
\end{tabular}




\begin{tabular}{|l|l|}
\hline C3, DLnCopper & 297 \\
\hline C4, DLnTWDol & 216 \\
\hline C5, DLnSP500 & 112 \\
\hline C6, DHYSpread & 220 \\
\hline
\end{tabular}

Graph 2. Rolling Fed Assets coefficients.

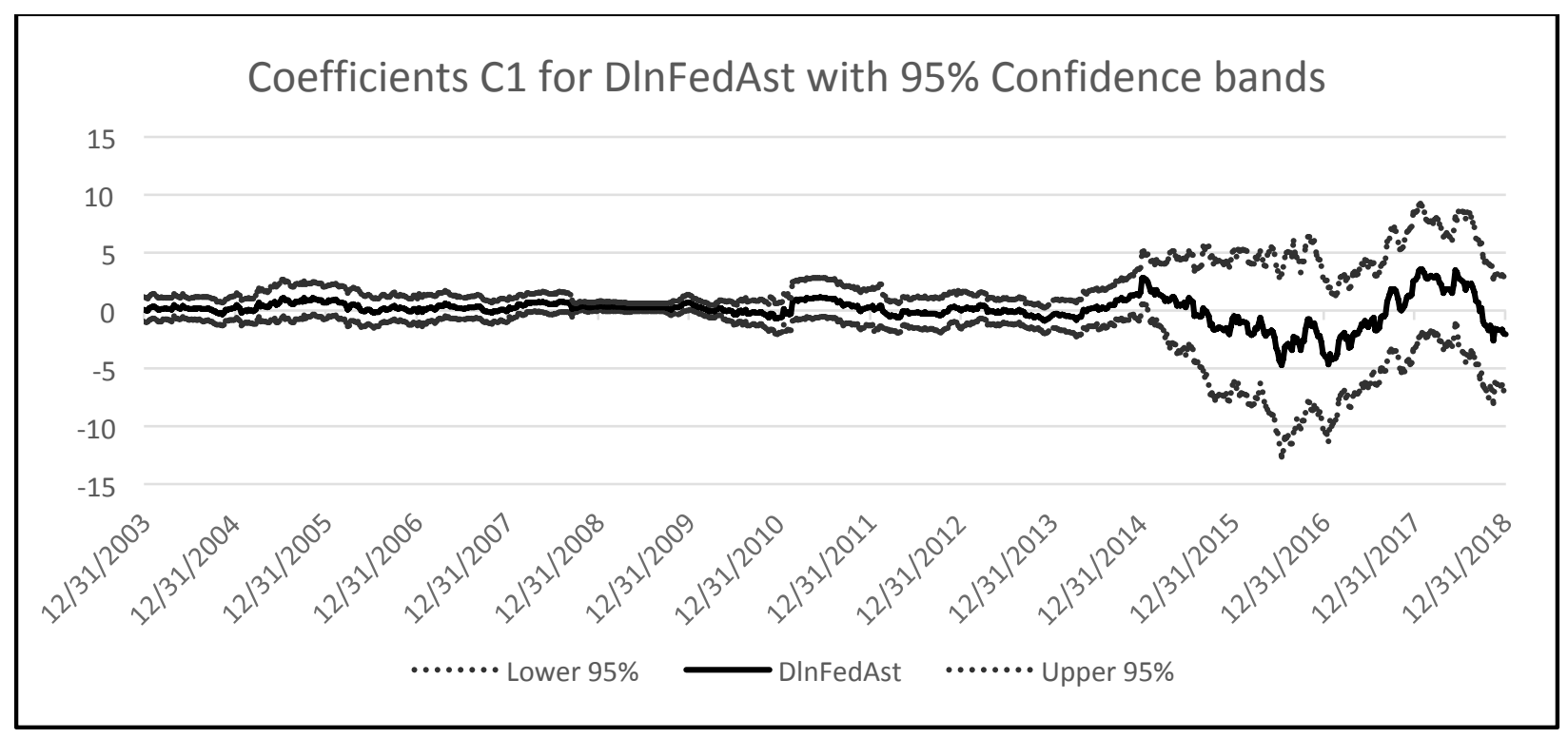

The coefficient c(1) in Graph 2 is very close to zero for a long period. Towards the end of the sample period, between the end of 2014 and the end of 2018, note that the coefficient c(1) remains on average zero but the significance bands become much wider. During this period there was no QE. With total Fed Assets remaining for most of this 4-year period around 4.5 trillion, this widening of the bands is a statistical consequence of regressing volatile oil prices to essentially constant Fed Assets during 2014 to 2016 and slowly declining assets from 2016 to 2018 when expiring bonds were not replaced in the stock of Fed Assets. During the first seven months of 2014, the price of oil was high, around \$100, but in June it started its steep decline and dropped to $\$ 50$ by December 2014. So, for the first several months in 2014 , oil markets behaved bullishly in view of QE3, but as the economy was recovering and the Fed decided against any additional QE, oil markets became bearish. 
Graph 3 presents the values of coefficient c(2). In general, lower 10-Year Treasury Note rates stimulate economic growth and oil prices increase. So declines in the T-Note rate may correlate with increases in the price of oil. However, if the T-Note rates decline because of a weak economy, then such longer-term interest declines may correlate with declines in the price of oil. To complicate things further, the global price of oil is affected not only by the U.S. economy but also by the rest of the world as well. When the Fed uses QE to lower longer-term interest rates while emerging markets such as China and India are growing rapidly, the net result may be increases in the price of oil. Thus the net effect on oil prices depends upon the magnitude of all the interacting components.

\section{Graph 3. Rolling Treasury Rate coefficient}

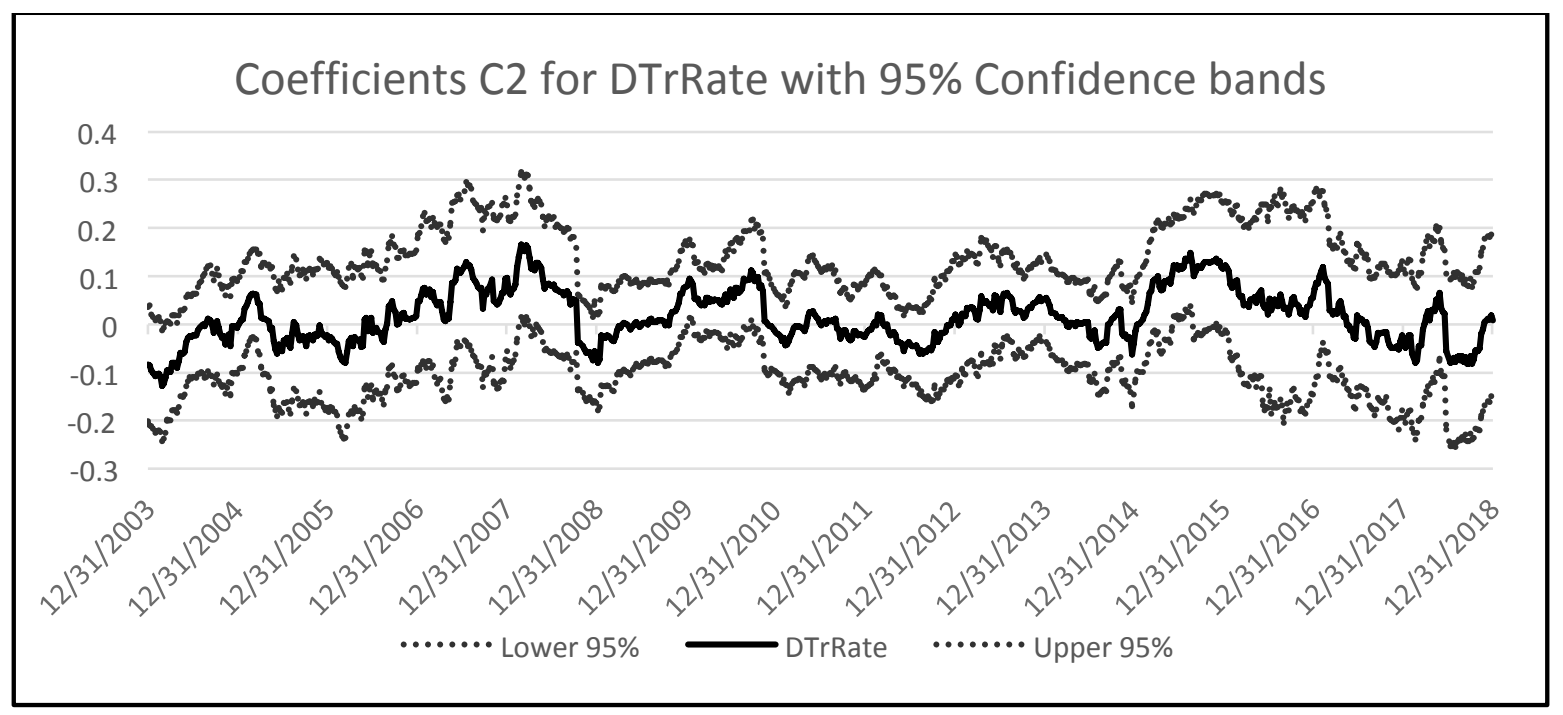

Graph 3 depicts a coefficient $\mathrm{c}(2)$ that fluctuates around zero and was significant only 23 out of 771 times. Changes in 10-Year Treasury Note rates sometimes move in the same direction as oil price changes while in other periods the relationship becomes negative. During a period of a strong economy, it is likely for long-term interest rates to increase as the price of oil also increases. Briefly, from Table 1 and Graphs 2 and 3 we conclude that both Fed Assets and 
the 10-Year Treasury Note rate are not often significant variables in the determination of global oil prices.

Next, we discuss, the copper coefficients illustrated in Graph 4.

\section{Graph 4. Rolling Copper coefficients}

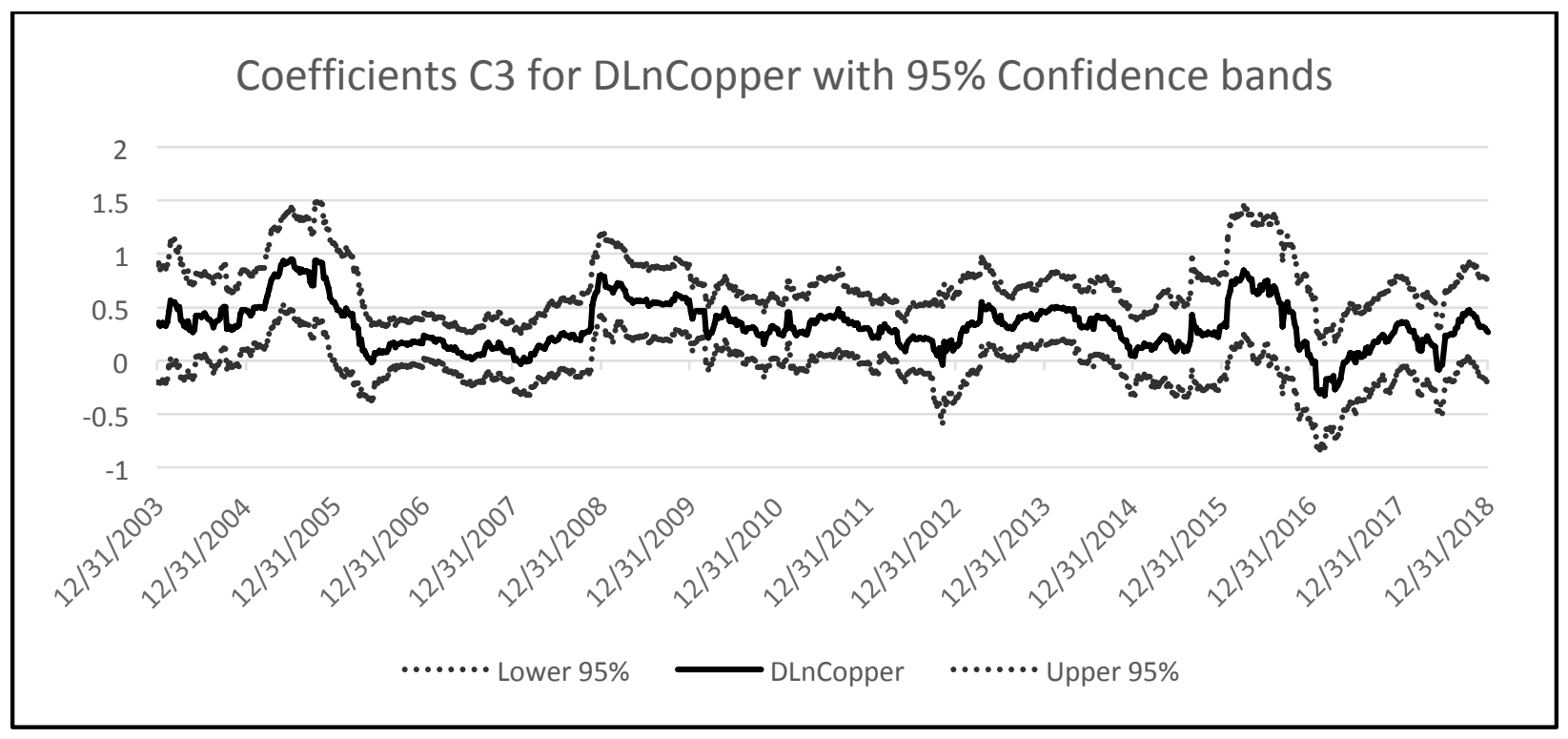

In model (1), we introduced copper as a proxy for the overall demand for commodities, primarily for developing countries. The price of copper and the price of oil display quite similar price patterns and this similarity is due to similar dynamics in terms of supply and demand. Hammoudeh, Chen and Fattouh (2010) give a detailed analysis of the behavior of cash and futures markets, with an emphasis on asymmetries, for the oil and copper markets, among other metals such as gold and silver.

Oil and copper have many uses, so their demand is influenced by overall economic conditions. Crude oil is refined into petroleum used to move vehicles, heat buildings and produce electricity, while copper has wide ranging applications in industrial production, 
electrical equipment, transportation and others. Mature economies such as the U.S., the European Union, Japan and others have a stable demand for copper and oil while demand in emerging countries such as China, India, Brazil that were growing rapidly during the past two decades have pushed up both oil and copper prices. We see that $\mathrm{c}(3)$ is positive with very minor exceptions. A minor exception occurred during 2018 when copper prices declined as oil prices were increasing. Table 1 confirms that copper's significance occurred in 297 rolling regressions out of a total of 771 .

\section{Graph 5. Rolling coefficients for the Trade Weighted Dollar}

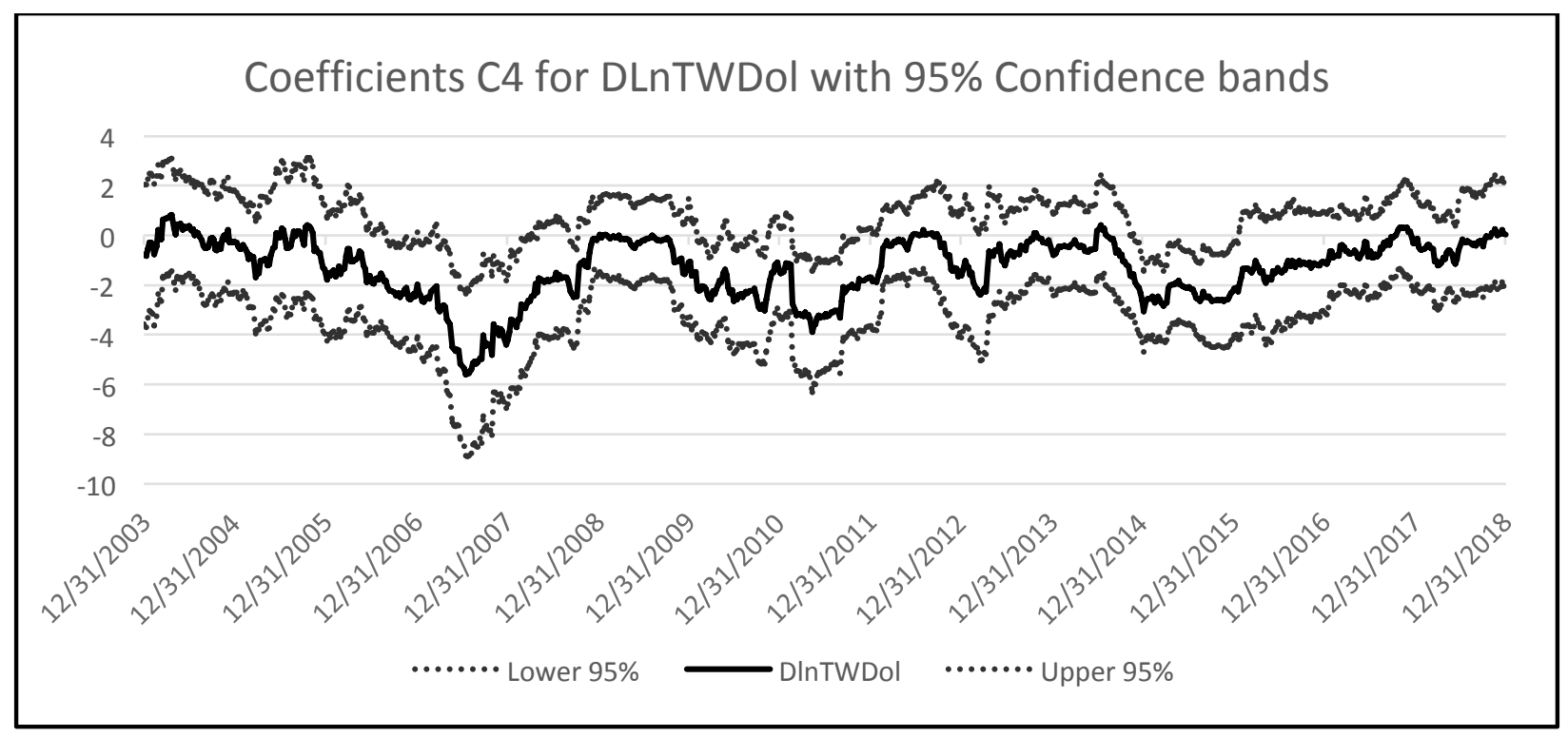

Graph 5 illustrates the coefficient c(4) for the Trade Weighted U.S. Dollar Index. When this Index increases it means that the U.S. dollar is getting stronger. A stronger dollar buys, for example more euros or more Japanese yen. Since the price of oil is expressed in U.S. dollars in the global market for oil, if the dollar strengthens against both the euro and the yen, Germany and Japan will pay more of their own currency to buy oil. Most likely, when the dollar strengthens, on average oil importing nations will decrease their oil imports and conversely, if 
the dollar weakens, the currencies of other nations on average will strengthen and be able to import more. Graph 5 confirms this negative pattern for $\mathrm{c}(4)$.

Graph 6 illustrates the coefficient $\mathrm{c}(5)$ that captures the impact of the U.S. stock market, as measured by the S\&P 500 Index, on oil. This index is a measure of the assessment of all market participants about the future prospects of the U.S. economy. This assessment is quite complex because it involves quantitative expectations about future firms' earnings, dividends, their growth prospects as well as estimates for an appropriate discount factor. These calculations are both technical and rational but also influenced by complex behavioral factors. It is difficult a priori to hypothesize a positive or negative relationship between the price of oil and the S\&P 500 Index. If the S\&P 500 Index is doing well and gradually increasing, such positive expectations about the future of the economy can translate into higher prices for oil; however, if the price of oil increases rapidly, such higher prices may produce inflation, discourage consumers and slow down the economy. Graph 6 exhibits this pattern for $\mathrm{c}(5)$ that fluctuates above and below zero.

Graph 6. Rolling coefficients for the S\&P 500

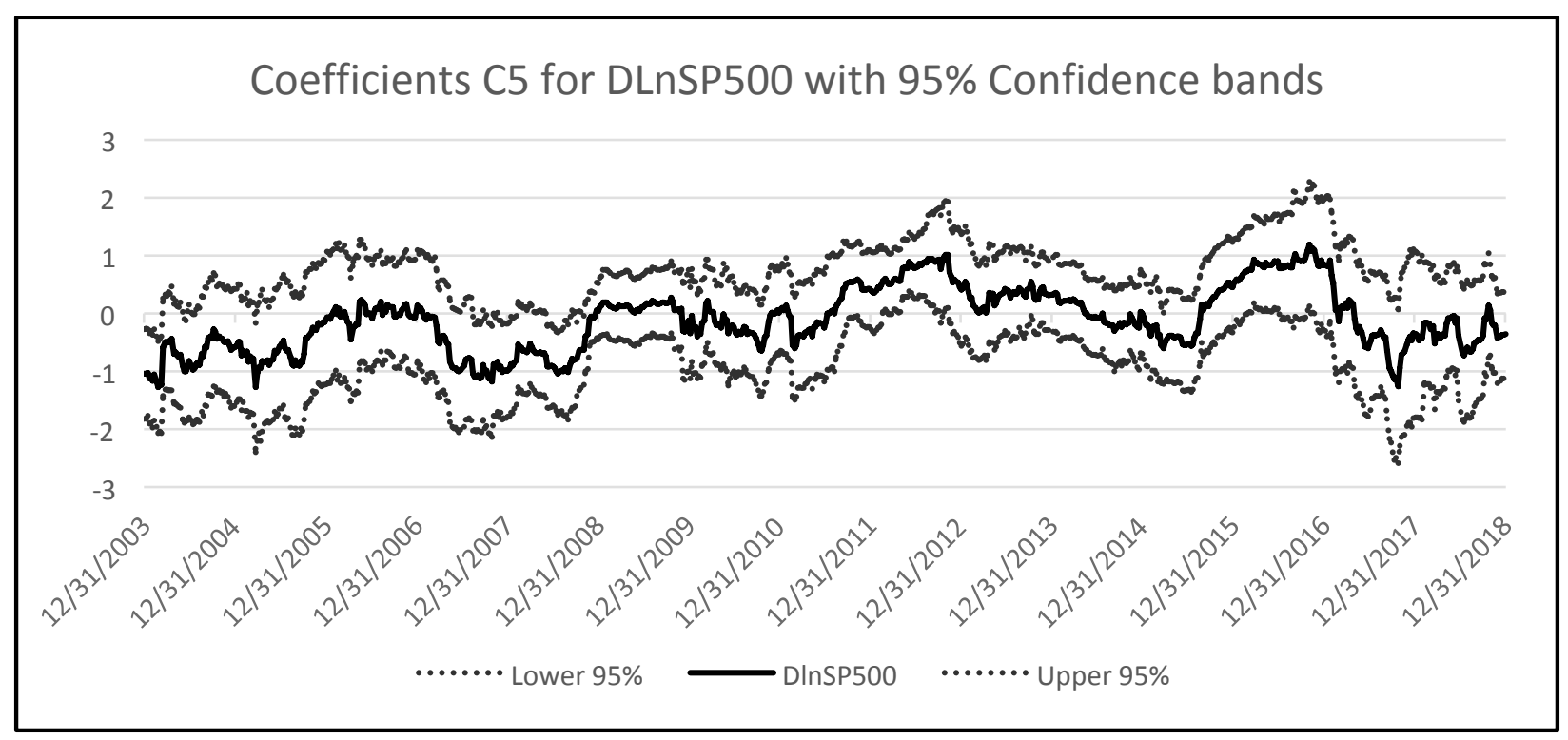


Next, we discuss the impact of coefficient c(6) for the High Yield rate. Recall that this rate is a measure of riskiness expressed as the CCC Bond computed option-adjusted spread of all bonds in a given rating category and a spot Treasury curve. Recall, we use this U.S. High Yield rate to measure the riskiness of junk bonds financing oil exploration and production in the U.S. Such riskiness impacts the borrowing costs of oil exploration and production and thus U.S. oil supply. This High Yield rate skyrocketed during the months of the financial crisis from August 2008 to late 2009, but after QE was launched it gradually declined and sharply increased again in June 2014 when the price of oil declined.

In section 3, we discussed that QE was implemented to decrease longer-term risk free Treasury bond rates for various maturities. These in turn, via what Bernanke (2010) called the portfolio-balance channel, would cause declines in corporate bond rates, stimulating borrowing, investments and economic growth. We described this as the direct influence of QE. Apergis (2019) supplies detailed evidence that credit spreads exhibited similar behavior in the Eurozone because of QE policies undertaken by the European Central Bank. Applying this logic to the oil industry, we argued that lower longer-term U.S. High Yield rates would encourage oil production increases that may bring eventually decreases in oil prices. This means we would expect coefficient $\mathrm{c}(6)$ to be positive.

Graph 7 illustrates that the calculated coefficients for c(6) fluctuate around zero with varying confidence bands. From 2003 to the middle of 2008, c(6) is mostly positive with small increases in the High Yield rate correlating with increases in the price of oil. During the Crisis, from September 2008 to mid-2009, the price of oil collapsed and the High Yield rate skyrocketed, so c(6) is negative. After 2009 to the end of 2018 most c(6) are negative. What is a 
reasonable explanation for the observed negative coefficients? Recall our discussion in section 3 about the indirect impact of QE. As QE grows, longer term interest rates decline and eventually High Yield rates also decline, reducing borrowing costs for oil exploration and production. A negative coefficient $\mathrm{c}(6)$ says that the observed lower High Yield rates are statistically associated with higher oil prices. During the 2009 to mid-2014 period, high oil prices and low High Yield rates kindled big increases in the exploration and production of oil. A negative coefficient is also consistent with increasing High Yield rates and decreasing oil prices. This is because decreasing oil prices, influenced, for example, by soft global weakness in demand, increase risks associated with valuations of future oil production financed by junk bonds and thus High Yield rates are increased. This is what happened after mid-2014.

\section{Graph 7. Rolling coefficients for the High Yield Spread}

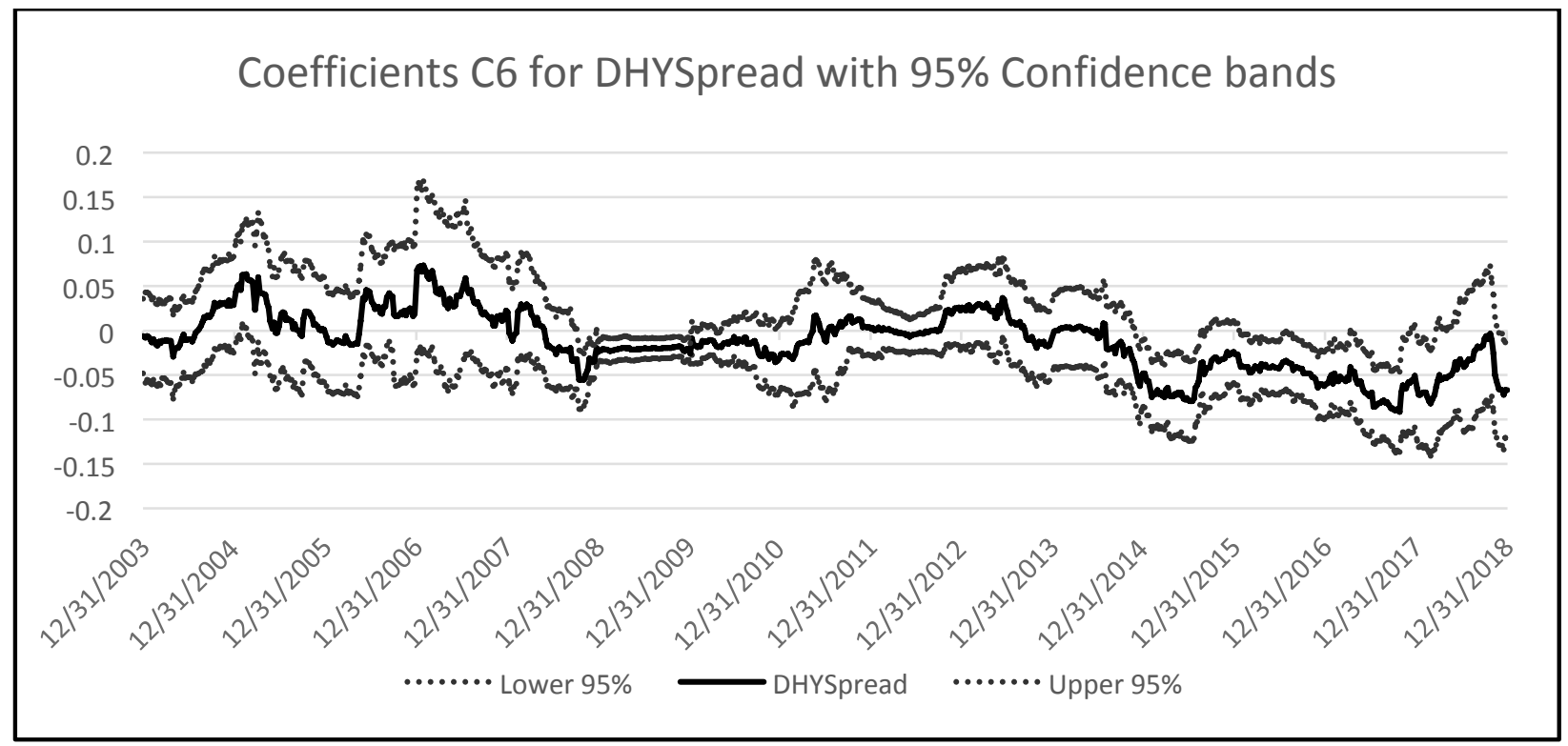

Baumeister and Kilian (2016b and 2016c) give an excellent analysis of the causes and consequences of the June 2014 decline in the price of oil and the dramatic increases in High 
Yield rates. They explain that oil investments during this period were driven by the price of oil.

The authors say:

"It is widely accepted that the unprecedented expansion of the U.S. shale oil sector has been a major contributor to aggregate investment since 2010, changing the dynamics of the U.S. economy. As a result, when the price of oil fell after June 2014, real investment in the U.S. oil sector dropped sharply, which could help explain why U.S. aggregate real nonresidential investment did not expand nearly as much in response to lower oil prices, as one might have expected. Baumeister and Kilian (2016c page 323)”.

Thus, we conclude cautiously that the impact of QE in the case of the oil industry was indirect and also limited because the declines in High Yield rates encouraged investments in production of oil as long as oil prices were high and expected to stay high. High oil prices increased the expected valuation of collateralized future production and reduced associated risks. When increases in U.S. production along with weakness in global demand caused oil prices to collapse in June 2014, unintended consequences of bankruptcies occurred for U.S. oil producing firms, certainly unanticipated by QE.

\section{CONCLUSIONS}

Our contribution consists of three components: the development of a financial model to explain the behavior of oil prices during 2003-2018; the use of the methodology of rolling regressions to capture the short-run dynamics of oil; and, the empirical results that are both insightful and surprising. The model is developed by financial reasoning after a careful review of the oil literature and the role of unconventional monetary policy during the Global Financial Crisis. The methodology employed is overlapping 52-week regressions that establish the empirical validity of the model and give precise statistical information about the relative behavior of the six inputs across 771 regressions. 
We find that all six independent variables behave according to economic reasoning and the R-square indicates that the proposed six independent variables each have a high correlation with the price of oil at some time during 2003-2018. The insights obtained include that QE with its program to purchase Treasury assets played a small role directly, judging by the significance of its coefficient. The same is true about the role and the impact of 10 -Year Treasury Note rate. Bernanke (2014) claims that QE was effective in decreasing Treasury yields as their prices were increasing with the Fed's intervention as a buyer in this market. Our work shows that the behavior of Treasury rates does not explain the price of oil with strong significance.

Additional insights obtained from the testing of our financial model include the significance of the price of copper, the Trade Weighted dollar and the S\&P 500 Index. These 3 inputs have been recognized for their importance in the current literature on oil and this study reconfirms their significance. The surprising result is the role of the U.S. High Yield rate. Our empirical results support the significance of the U.S. High Yield rate as a determinant of the price of oil but with, predominantly, a negative coefficient. A negative coefficient means that decreases in the U.S. High Yield rate are related with increases in oil prices and conversely. To the extent that U.S. High Yield rates were reduced by QE, new investments in oil exploration and production were driven by borrowing at lower rates. This increased the U.S. oil production, particularly between 2012 to mid-2014, when the oil industry borrowed with junk bonds debt, invested heavily in oil exploration, and production and oil output increased dramatically. However, the collapse in oil prices that started in June 2014 increased the U.S High Yield rate dramatically because debt financed explorations and production were collateralized on future output valued at high oil prices. Reassessments at much lower oil prices increased risks of oil 
firms saddled with big loans and reduced future earnings. New investments came to a standstill and existing firms faced bankruptcies. Such outcomes were not intended, nor anticipated by QE.

Thus, our financial model demonstrates a surprising dimension of the unintended consequences of $\mathrm{QE}$ on the global oil market. To the extent $\mathrm{QE}$ achieved the reduction of longerterm interest rates that stimulated investments and reduced unemployment, this sequence of development is certainly positive. However, if this sequence is extended dynamically to also include increased risks in the sequel for certain sectors such as the oil industry, expressed in our paper with the introduction of the U.S. High Yield rate as a new variable in the oil literature, revisiting both the benefits as well as the potential risks of QE may be appropriate.

\section{REFERENCES}

Apergis, N. (2019), "The role of the expectations channel in the quantitative easing in the Eurozone", Journal of Economic Studies, 46(2):372-382.

Barsky, R. and Kilian, L. (2001), "Do We Really Know That Oil Caused the Great Stagflation? A Monetary Alternative", NBER Macroeconomics Annual, 16: 137-183.

Baumeister, Christiane and Lutz Kilian (2016a), "Forty Years of Oil Price Fluctuations: Why the Price of Oil May Still Surprise Us", The Journal of Economic Perspectives, 30(1): 139-160.

Baumeister, Christiane and Lutz Kilian, (2016b), "Understanding the Decline in the Price of Oil Since June 2014" (February 15, 2016). CESifo Working Paper Series No. 5755. Available at SSRN: https://ssrn.com/abstract=2747889

Baumeister, Christiane and Lutz Kilian, (2016c), "Lower Oil Prices and the U.S. Economy: Is This Time Different?” Brookings Papers on Economic Activity, pp. 287-336.

Bernanke, B., Gertler, M. and Watson, M. (1997), "Systematic Monetary Policy and the Effects of Oil Price Shocks (with discussion)", Brookings Papers on Economic Activity, 1997(1): 91157.

Bernanke, Ben S. (2010), "The Economic Outlook and Monetary Policy." Speech at the Federal Reserve Bank of Kansas City Economic Policy Symposium, Jackson Hole, Wyoming, August $27,2010$. 
Bernanke, Ben (2012), "Monetary Policy Since the Onset of the Crisis", Remarks at the Federal Reserve Bank of Kansas City Economic Symposium, Jackson Hole, Wyoming, August 31, 2012.

Bernanke, Ben (2014), "The Federal Reserve: Looking Back, Looking Forward”, at the Annual Meeting of the American Economic Association, Philadelphia, Pennsylvania, January 3, 2014.

Bernanke, Ben (2020), "The New Tools of Monetary Policy”, Presidential Address at the American Economic Association Meetings, San Diego, California, January 4, 2020.

Bhar, R. and Malliaris, A., (2011), "Oil Prices and the Impact of the Financial Crisis of 20072009." Energy Economics, 33: 1049-1054.

Bhar, Ramaprasad, A. G. Malliaris and Mary Malliaris, (2015), "The Impact of Large-scale Asset Purchases on the S\&P 500 Index, Long-term Interest Rates, and Unemployment, Applied Economics, 47(55):6010-6018.

Cashin, P., K. Mohaddes, Maziar Raissi and Mehdi Raissi (2014), "The Differential Effects of Oil Demand and Supply Shocks on the Global Economy", Energy Economics, 44:113-134.

Dickey, D. A. and W.A. Fuller (1981), "Likelihood ratio Statistics for Autoregressive Time Series with a Unit Root", Econometrica, 49:1057-72.

Hamilton, James D. (1983), “Oil and the Macroeconomy Since World War II”, Journal of Political Economy, 91:228-48.

Hamilton, James D. (1985), "Historical Causes of Postwar Oil Shocks and Recessions", The Energy Journal, 6(1):97-116.

Hamilton, James D. (2009), “Understanding Crude Oil Prices”, The Energy Journal, 30:179-206.

Hammoudeh, Shawkat, Li-Hsueh Chen and Bassam Fattouh, (2010), “Asymmetric Adjustments in Oil and Metal Markets", The Energy Journal, 31(4):183-203.

Kilian, Lutz, (2008), "Exogenous Oil Supply Shocks: How Big Are They and How Much Do They Matter for the U.S. Economy?” Review of Economics and Statistics, 90:216-40.

Kilian, Lutz (2009), "Not All Oil Price Shocks Are Alike: Disentangling Demand and Supply Shocks in the Crude Oil Market", The American Economic Review, 93(3):1053-1069.

Kuttner, Kenneth (2018), "Outside the Box: Unconventional Monetary Policy in the Great Recession and Beyond", The Journal of Economic Perspectives, 32(4):121-146.

Malliaris, A. G. and Malliaris, Mary, (2018), "Modelling Oil Pricing Across Different Regimes: A Neural Network Methodology" (November 9, 2018). Available at SSRN:

https://ssrn.com/abstract=3281185 or http://dx.doi.org/10.2139/ssrn.3281185

Morana, Claudio, (2013), “The "Oil-Macroeconomy Relationship Since the Mid-1980s: A Global Perspective”, The Energy Journal, vol. 34, pp. 131-156.

Narayan, Presh Kumar and R. Gupta, (2015). "Has Oil Price Predicted Stock Returns for Over a Century? Energy Economics, 48, pp. 18-23. 
Pinno, Karl and Apostolos Serletis, (2013), "Oil Price Uncertainty and Industrial Production", The Energy Journal, 34(3):191-216.

Salvatore, Dominick, (2010), "The Global Financial Crisis: Predictions, Causes, Effects, Policies, Reforms and Prospects," The Journal of Economic Asymmetries, 7(2): 1-20.

Smith, James (2009), “World Oil: Market or Mayhem?” The Journal of Economic Perspectives, 23(3): 145-164.

Tsai, C.L., (2015), "How Do US Stock Returns Respond Differently to Oil Price Shocks PreCrisis, Within the Financial Crisis, and Post-Crisis?" Energy Economics, 50:47-62.

Yin, L. and Zhou, Y. (2016). What Drives Long-term Oil Market Volatility? Fundamentals versus Speculation. Economics: The Open-Access, Open-Assessment E-Journal, 10 (2016-20): 1-26. http://dx.doi.org/10.5018/economics-ejournal.ja.2016-20

\footnotetext{
${ }^{1}$ The authors are grateful to numerous conference participants for questions asked, remarks made and suggestions offered that contributed to significant improvements in both expository clarity and scientific improvements. Most recently, this paper benefited from presentation at the $26^{\text {th }}$ Annual Conference of the Multinational Finance Society, Jerusalem, Israel, June 30- July 3, 2019 and Sixth Annual Conference of the Society for Economic Measurement, Goethe University, Frankfurt, Germany, August 15 -18, 2019. In particular, the authors are thankful to Peter Theodossiou, Apostolos Serletis and Fakhri Hasanov for detailed comments.

${ }^{2}$ We realize that it is most likely that we have omitted additional candidates. To address the issue, we introduced some fundamental variables to augment equation (1). We did so by adding two new variables one at a time. First, we added $\mathrm{D}(\log$ of $\mathrm{P}$ of Oil at $\mathrm{t}-1)$ and re-ran all 771 regressions and compared the R-squared from our model versus the one augmented by the new variable to only find insignificant improvement. Second we added the weekly data of Oil Stocks excluding the Strategic Petroleum Reserve as in Malliaris and Malliaris (2018) and again re-ran all our regressions observing no significant improvement. Thus we concluded that these fundamental variables added to the equation, judged by this sampling, do not enrich our financial model and were not included in the final run.

${ }^{3}$ The standard Unit Root tests (Dickey Fuller, KPSS and Phillips-Peron) were performed, confirming stationarity.
} 